\title{
Thomsen and Becker disease
}

INSERM

\section{Source}

INSERM. (1999). Orphanet: an online rare disease and orphan drug data base. Thomsen

and Becker disease. ORPHA:614

Myotonia congenita is characterised by slow muscle relaxation associated with hyperexcitation of the muscle fibres. 